\title{
The potential clinical applications and prospects of microRNAs in lung cancer
}

This article was published in the following Dove Press journal:

OncoTargets and Therapy

4 June 2014

Number of times this article has been viewed

Ying Gao'

Fei $\mathrm{Gao}^{2, *}$

Jin-lu Ma',*

Wen-ze Sun'

Li-ping Song'

'Department of Radiotherapy

Oncology, First Affiliated Hospital

of Medical College of Xi'an Jiaotong

University, ${ }^{2}$ Department of Neurology,

First Affiliated Hospital of Xi'an

Medical University, Xi'an, People's

Republic of China

*These authors contributed equally to this work
Correspondence: Ying Gao

Department of Radiotherapy Oncology, First Affiliated Hospital of Medical

College of Xi'an Jiaotong University, Xi'an

71006I, People's Republic of China

Tel +86298532 4019

Email togaoying@163.com
Abstract: Lung cancer is the major cause of cancer deaths worldwide due to its late diagnosis and poor outcome. Understanding genomic medicine may widen our vision into the oncogenesis of lung cancer and may open the door to improvements in the clinical management of lung cancer. It is well known that almost half of all genes are regulated by microRNAs (miRNAs). This review focuses on the role of miRNAs in lung cancer and also touches on the value of miRNA-based novel therapies for lung cancers.

Keywords: microRNA, lung cancer, biomarker, chemotherapy, radiotherapy

\section{Introduction}

Lung cancer is the most common invasive cancer and cause of cancer death worldwide, and in all cases, non-small-cell lung cancer (NSCLC) accounts for approximately $80 \% .^{1-3}$ Although novel therapies have been developed, the 5-year survival rate for NSCLC patients remains at a low $15 \% .{ }^{4}$ Therapy in NSCLC has reached a plateau. The unfavorable outcome is due to our relatively limited understanding of tumor gene expression profiles and pathogenesis. Thus, understanding genomic medicine may therefore aid investigations into the oncogenesis of lung cancer. It may also yield prospects in accurate new biomarkers, molecular diagnosis, and risk stratification of lung cancer.

In the recent years, the changes in expression levels of microRNAs (miRNAs) have been detected and described. miRNA plays a significant role in a wide variety of pathways by regulating gene expression at the posttranscriptional level. It is well known that almost half of all genes are regulated by miRNAs as they are located in cancer-associated genomic regions or fragile genomic sites. ${ }^{5}$ For example, miR-128b directly regulates epidermal growth factor receptor. Emerging evidence suggests that miRNAs may control lung cancer development and play a critical role in its oncogenesis and pathogenesis. ${ }^{6-14}$ Since miRNAs play a substantial role and detection samples can easily be obtained, they have become a promising means of comprehending the oncogenesis and pathogenesis of lung cancer. miRNAs may contribute to drug efficacy and serve as outcome predictors in lung cancer.

In this review, we briefly describe the roles of miRNAs in lung carcinogenesis, diagnosis, prognosis, and their potential roles in lung cancer therapy.

\section{Features of miRNAs}

miRNAs are endogenous noncoding and small (20-22 nucleotides) RNAs that have pivotal functions in biological processes. ${ }^{15,16}$ miRNAs can regulate gene expression 
at the posttranscriptional level; therefore, they control fundamental cellular activities such as cell growth, differentiation, proliferation, and apoptosis. miRNAs have the potential to regulate at least $20 \%-30 \%$ of all human transcripts, ${ }^{17}$ thereby involving them in almost all basic signaling pathways. Furthermore, miRNAs can control the expression of important tumor-related genes in tumorigenesis, including oncogenes and tumor-suppressor genes. ${ }^{18}$ Thus, dysregulated miRNAs contribute to a variety of pathological events.

\section{miRNAs as tumor inhibitors or oncogenes in lung cancer}

Several studies have showed an important role of miRNAs in the regulation of carcinogenesis in different organs and the cell cycle, leading to the study of miRNAs as regulators of oncogenes and tumor inhibitor genes. Overexpression of let-7a, miR-126, and miR-107 suppresses lung cancer cell growth. ${ }^{19}$ It has been reported that the inhibition of let-7 with an anti-let-7 molecule results in a $100 \%$ increase in the number of A549 cells. ${ }^{20}$ Kumar et al ${ }^{20}$ not only showed the ectopic expression of let-7g induced both cell cycle arrest and cell death in lung cancer cells, but also demonstrated that let-7g expression substantially reduced lung tumor burden in an autochthonous model of NSCLC. It has been concluded that cell growth is inhibited by the overexpression of let-7 miRNA, functioning as a tumor suppressor, suggesting the miRNA let-7 family functions as a tumor inhibitor. ${ }^{8,21,22}$

Aside from the let-7 family, miR-29a has been confirmed to reduce invasiveness and proliferation of human carcinoma cell lines. ${ }^{23-25}$ miR-29b significantly reduced migration and invasion, and miR-218 is a strong candidate tumor suppressing miRNA, potentially involved in lung cancer. ${ }^{26}$ The miR-451 was found to be significantly associated with tumor differentiation, pathological stage, and lymph node metastasis. ${ }^{27}$ Furthermore, it was observed that low miR-451 expression levels were also associated with shorter overall survival of NSCLC patients, and miRNA-451 could function as a tumor inhibitor in human NSCLC by targeting ras-related protein 14 (RAB14). ${ }^{27}$ Further, miRNAs such as miR-98, miR-101, miR-93, miR-182, miR197, miR-212, and miR-451 have tumor-suppressive functions in lung cancer. ${ }^{28-32}$

Conversely, several miRNAs function as oncogenes to promote tumor progression by inhibiting tumor suppressor genes. Oncogene overexpression is correlated with increased cell proliferation. ${ }^{33}$ The polycistronic cluster miR-17-92 is involved in embryonic lung development, consisting of six miRNAs (miR-17, miR-18a, miR-19a, miR-19b-1, miR-20a, miR-92a-1). ${ }^{34}$ miR-125a-5p upregulates several downstream genes involved in epidermal growth factor receptor signaling and is associated with lung cancer invasion and metastasis. ${ }^{35}$ In addition, it has been shown that miR-31 functions as an oncogenic miRNA by repressing specific tumor suppressors. ${ }^{36}$ The engineered knockdown of miR-31 substantially repressed lung cancer cell growth and tumorigenicity in a dose-dependent manner. ${ }^{36}$

The literature suggests that miRNAs might regulate their expression by influencing their epigenetic regulation within the tumor and act directly by targeting oncogenes or tumor suppressor genes. Recently, a novel mechanism has shown that miRNAs also affect lung carcinogenesis by triggering a toll-like receptor-mediated oncogenic inflammatory response. However, miRNAs are involved in lung cancer carcinogenesis through various mechanisms.

\section{miRNAs as biomarkers for chemoresistance or chemosensitivity in NSCLC}

Mechanisms of drug resistance are often associated with changes in relevant proteins, such as PDCD4, PTEN, multidrug resistance 1, and P-glycoprotein. Several studies have discussed that aberrant miRNA expression can be related to chemotherapy resistance by resulting in altered function of the target mRNA, which affects the expression of the target proteins and fundamentally silences the target gene. ${ }^{37}$

Current investigations of miRNAs related to chemoresistance have been reported in the literature. They support the hypothesis that the overexpression or underexpression of any miRNA is directly linked to a patient's response to chemotherapeutic agents. miR-92a-2* and miR-574-5p were significantly associated with chemoresistance in small cell lung cancer (SCLC), with higher tumor miR-92a-2* levels related to chemoresistance and decreased survival in patients. Thus, miR-92a-2* may be applied in the screening of patients with SCLC at risk for de novo chemoresistance and predict chemoresistance for SCLC. These miRNA biomarkers may contribute to treatment stratification. ${ }^{38}$

Recently, Xie et al $^{39}$ showed that cell-free miRNAs in the supernatant of effusions may predict chemosensitivity to docetaxel. A number of miRNAs have been shown to be differentially expressed in docetaxel-resistant NSCLC, as demonstrated by specifically increased levels of miR-192, miR-98, and miR-424 and decreased levels of miR-200b, miR-194, and miR-212. ${ }^{40}$ miR-497 was downregulated in the multidrug-resistant human lung cancer cell line A549/ cisplatin; an overexpression of miR-497 sensitized A549/ cisplatin cells to anticancer drugs. ${ }^{41}$ It was also found 
that miR-200c overexpression restored the sensitivity of NCI-H1299 cells to cetuximab and cisplatin. ${ }^{42}$

Chemoresistance is implicated in epithelial-mesenchymal transition (EMT) or stem cell trait of cancer cells, which can be regulated by miRNAs. One study found that the miR-181aTwist 1 pathway played a key role in the development of cisplatin chemoresistance with EMT, which increased the metastatic potential of tongue squamous cell carcinoma. ${ }^{43}$ Functional analyses indicated that miR-181a reversed chemoresistance, inhibited EMT, and decreased metastatic potential in tongue squamous cell carcinoma cells. Cisplatin-induced chemoresistance underwent EMT and was accompanied by enhanced metastatic potential, miR-181a downregulation, and Twist1 upregulation. ${ }^{43}$ Emerging evidence also proved that the miR-200 family are downregulated in cancer and play an important role in the suppression of EMT, tumor progression, and chemoresistance by targeting and repressing the expression of several key messenger RNAs. ${ }^{44}$

Various studies clearly demonstrate the role of miRNAs in chemosensitivity and chemoresistance, suggesting the manipulation of miRNAs may be beneficial in modulating cancer chemosensitivity and chemoresistance. miRNAs serve as the most accurate predictive biomarkers in providing the most precise prognosis for treatment response and outcomes, establishing personalized medicine currently available in the market. ${ }^{67}$ It is anticipated that the therapeutic development of miRNA mimics or antagomirs may improve prognosis for NSCLC and reveal novel therapies. Therefore, miRNAs should be used firstly, as biomarkers to predict drug resistance or sensitivity in order to establish the appropriate personalized treatment and secondly, as possible drug targets to reverse resistance.

\section{miRNAs as biomarkers for radioresistance or radiosensitivity in NSCLC}

The resistance of hypoxic cells to radiotherapy is also a major problem in the treatment of cancer. Recently, an additional mode of hypoxia-inducible factor (HIF)-dependent transcriptional regulation has emerged. Grosso et $\mathrm{a}^{45}$ have recently shown that miR-210 appears to be a component of the radioresistance of hypoxic cancer cells. Given the high stability of most miRNAs, such as in the case of HIF-1 induction of miR-210 which also stabilizes HIF-1 through a positive regulatory loop, this advantage could be used by tumor cells where reoxygenation has occurred and implies that strategies targeting miR-210 could enhance tumor radiosensitization. ${ }^{45}$
miR-34 is another important miRNA involved in p53-mediated apoptosis. The overexpression of p53 activated miR-34a/SIRT1/p53, which in turn was inhibited by ursodeoxycholic acid via decreased p53 transcriptional activity. ${ }^{46}$ Another study demonstrated that restoration of miR-34a expression enhanced radiation-induced apoptosis, partly by suppressing the LyGDI signaling pathway. miR-34a could be used as a radiosensitizer since it is transcriptionally induced by the tumor suppressor gene p53 and is often downregulated in NSCLC. ${ }^{47}$ In addition, some miRNAs are demonstrated to be epigenetically silenced by DNA methylation, while DNA methylation is associated with chemotherapy and radiotherapy cross-resistance, and finely balanced DNA methylation is needed to ensure proper radiation and drug responsiveness. . $^{48,49}$

Let-7a and let-7b were also shown to radiosensitize lung cancer cells and probably so do other members in the let-7 family, except let-7g for which it was confirmed the expression pattern changes after irradiation. ${ }^{50-52}$ Let-7g was shown to be radiosensitizing in two studies but radioprotective in another study for lung cancer cells. ${ }^{50-52}$ miR-26b was reported to radiosensitize lung cancer cells, ${ }^{50-52}$ whereas miR-9, miR155, miR-126, and miR-7 had the opposite effect. ${ }^{52-56}$ In this situation, combining miRNA mimics or inhibitors with traditional therapies may potentiate the efficacy of the treatment, but more research is required to address this question..$^{50-56}$

\section{Clinical implications in NSCLC} miRNA based therapies for lung cancer

With the significant roles that miRNAs play in the prognosis and diagnosis of lung cancer, increasing efforts are dedicated to the development of miRNA-based therapies. There is great interest in the potential application of the restoring functions of tumor suppressive miRNAs and the inhibiting oncogenic miRNAs. ${ }^{57}$

Exogenous delivery of let-7 into mouse models of lung cancers significantly reduced tumor growth or decreased tumor burden. ${ }^{22,58-59}$ The results suggested that miRNA replacement therapy could be promising. Liposome-based delivery of miR-7 into mouse xenografts of lung tumors resulted in significant shrinking of the tumors, ${ }^{60}$ and an miR34a based strategy has also been proved effective in mouse lung cancer models. ${ }^{61,62}$ Several types of miRNA inhibitors have been developed to achieve therapeutic effects. A new class of miRNA inhibitors can be expressed in cells from transgenes of tandem miRNA binding sites linked to a strong promoter. ${ }^{63}$ A locked nucleic acid-anti-miR against miR-122 has been shown to effectively silence miR-122 in primates 
without evidence for toxicity. This suggests the feasibility of miRNA inhibitors for utilization in clinical settings. ${ }^{64}$ miRNAs are less toxic and capable of "multitargeting", pointing to their potential to enter clinical practice compared to small interfering RNA-based therapies, which are already in clinical trials. ${ }^{65}$ The critical issues for the development of this therapy are effective and fast delivery into target sites, potency of the therapy, and elimination of off-target effects. To solve these issues, double stranded miRNA mimics promise a cost-effective source, easier mechanism of function, and less nonspecific effects than mature miRNAs.

In general, miRNAs have theoretical and clinical implications in lung cancer settings since they play an important role in lung tissue and plasma as predictors of lung cancer development and aggressiveness. The results may improve the ability of clinicians to determine the most effective management for individual patients. The strategy, such as the integration of microarray-based genomic information with existing clinicopathological models, may improve survival rates and reduce treatment-related morbidity in patients with NSCLC. For example, Roybal et al ${ }^{66}$ concluded that miR-200 suppresses lung tumorigenesis by targeting Flt1, which correlates inversely with the duration of survival. This was based on the finding that forced miR-200 expression suppressed Flt1 levels, and Flt1 knockdown decreased the growth and metastasis of tumor cells. ${ }^{66,67}$ Although still in its infancy, further application prospects of miRNAs as biomarkers for chemo/radioresistance or chemo/radiosensitivity in NSCLC is anticipated, and these potential miRNA-based therapies are promising whether administered alone or in combination with conventional therapies.

\section{Acknowledgments}

This study was supported by the National Natural Science Foundation of China (Number 81301937) and the International cooperation foundation of Shaanxi Province of China (Number 2013KW-27-03).

\section{Disclosure}

The authors report no conflicts of interest in this work.

\section{References}

1. Ferlay J, Parkin DM, Steliarova-Foucher E. Estimates of cancer incidence and mortality in Europe in 2008. Eur J Cancer. 2009;46(4):765-781.

2. Ramalingam S, Pawlish K, Gadgeel S, Demers R, Kalemkerian GP. Lung cancer in young patients: analysis of a surveillance, epidemiology, and end results database. J Clin Oncol. 1998;16(2):651-657.

3. Jemal A, Siegel R, Ward E, Hao Y, Xu J, Thun MJ. Cancer statistics, 2009. CA Cancer J Clin. 2009;59(4):225-249.

4. Miller YE. Pathogenesis of lung cancer: 100 year report. Am J Respir Cell Mol Biol. 2005;33(3):216-223.
5. Esquela-Kerscher A, Slack FJ. Oncomirs - microRNAs with a role in cancer. Nat Rev Cancer. 2006;6(4):259-269.

6. Weiss GJ, Bemis LT, Nakajima E, et al. EGFR regulation by microRNA in lung cancer: correlation with clinical response and survival to gefitinib and EGFR expression in cell lines. Ann Oncol. 2008;19(6): 1053-1059.

7. He L, He X, Lim LP, et al. A microRNA component of the $\mathrm{p} 53$ tumour suppressor network. Nature. 2007;447(7148):1130-1134.

8. Johnson SM, Grosshans H, Shingara J, et al. RAS is regulated by the let-7 microRNA family. Cell. 2005;120(5):635-647.

9. Lu J, Getz G, Miska EA, et al. MicroRNA expression profiles classify human cancers. Nature. 2005;435(7043):834-838.

10. Calin GA, Croce CM. MicroRNA signatures in human cancers. Nat Rev Cancer. 2006;6(11):857-866.

11. Eder M, Scherr M. MicroRNA and lung cancer. $N$ Engl $J$ Med. 2005;352(23):2446-2448.

12. Gregory RI, Shiekhattar R. MicroRNA biogenesis and cancer. Cancer Res. 2005;65(9):3509-3512.

13. Volinia S, Calin GA, Liu CG, et al. A microRNA expression signature of human solid tumors defines cancer gene targets. Proc Natl Acad Sci U S A. 2006;103(7):2257-2261.

14. Hammond SM. MicroRNAs as oncogenes. Curr Opin Genet Dev. 2006;16(1):4-9.

15. Bartel DP. MicroRNAs: genomics, biogenesis, mechanism, and function. Cell. 2004;116(2):281-297.

16. Calin GA, Dumitru CD, Shimizu M, et al. Frequent deletions and down-regulation of micro-RNA genes miR15 and miR16 at 13q14 in chronic lymphocytic leukemia. Proc Natl Acad Sci U SA. 2002;99(24): 15524-15529.

17. Alexiou P, Maragkakis M, Papadopoulos GL, Reczko M, Hatzigeorgiou AG. Lost in translation: an assessment and perspective for computational microRNA target identification. Bioinformatics. 2009;25(23):3049-3055.

18. Iorio MV, Ferracin M, Liu CG, et al. MicroRNA gene expression deregulation in human breast cancer. Cancer Res. 2005;65(16): 7065-7070.

19. Zhong M, Ma X, Sun C, Chen L. MicroRNAs reduce tumor growth and contribute to enhance cytotoxicity induced by gefitinib in non-small cell lung cancer. Chem Biol Interact. 2010;184(3):431-438.

20. Kumar MS, Erkeland SJ, Pester RE, et al. Suppression of non-small cell lung tumor development by the let-7 microRNA family. Proc Natl Acad Sci U S A. 2008;105(10):3903-3908.

21. Johnson CD, Esquela-Kerscher A, Stefani G, et al. The let-7 microRNA represses cell proliferation pathways in human cells. Cancer Res. 2007;67(16):7713-7722.

22. Esquela-Kerscher A, Trang P, Wiggins J, et al. The let-7 microRNA reduces tumor growth in mouse models of lung cancer. Cell Cycle. 2008;7(6):759-764.

23. Wu X, Piper-Hunter MG, Crawford M, et al. MicroRNAs in the pathogenesis of lung cancer. J Thorac Oncol. 2009;4(8):1028-1034.

24. Xu H, Cheung IY, Guo HF, Cheung NK. MicroRNA miR-29 modulates expression of immunoinhibitory molecule B7-H3: potential implications for immune based therapy of human solid tumors. Cancer Res. 2009;69(15):6275-6281.

25. Muniyappa MK, Dowling P, Henry M, et al. MiRNA-29a regulates the expression of numerous proteins and reduces the invasiveness and proliferation of human carcinoma cell lines. Eur J Cancer. 2009;45(17): 3104-3118.

26. Davidson MR, Larsen JE, Yang IA, et al. MicroRNA-218 is deleted and downregulated in lung squamous cell carcinoma. PLoS One. 2010;5(9):e12560.

27. Wang R, Wang ZX, Yang JS, Pan X, De W, Chen LB. MicroRNA-451 functions as a tumor suppressor in human non-small cell lung cancer by targeting ras-related protein 14 (RAB14). Oncogene. 2011;30(23): 2644-2658.

28. Du L, Schageman JJ, Subauste MC, et al. miR-93, miR-98, and miR-197 regulate expression of tumor suppressor gene FUS1. Mol Cancer Res. 2009;7(8):1234-1243. 
29. Zhang JG, Guo JF, Liu DL, Liu Q, Wang JJ. MicroRNA-101 exerts tumor-suppressive functions in non-small cell lung cancer through directly targeting enhancer of zeste homolog 2. J Thorac Oncol. 2011;6(4):671-678.

30. Sun Y, Fang R, Li C, et al. Hsa-mir-182 suppresses lung tumorigenesis through down regulation of RGS17 expression in vitro. Biochem Biophys Res Commun. 2010;396(2):501-507.

31. Rothschild SI. Epigenetic Therapy in Lung Cancer - Role of microRNAs. Front Oncol. 2013;3:158.

32. Incoronato M, Garofalo M, Urso L, et al. miR-212 increases tumor necrosis factor-related apoptosis-inducing ligand sensitivity in nonsmall cell lung cancer by targeting the antiapoptotic protein PED. Cancer Res. 2010;70(9):3638-3646.

33. Hayashita Y, Osada H, Tatematsu Y, et al. A polycistronic microRNA cluster, miR-17-92, is overexpressed in human lung cancers and enhances cell proliferation. Cancer Res. 2005;65(21):9628-9632.

34. Lu Y, Thomson JM, Wong HY, Hammond SM, Hogan BL. Transgenic over-expression of the microRNA miR-17-92 cluster promotes proliferation and inhibits differentiation of lung epithelial progenitor cells. Dev Biol. 2007;310(2):442-453.

35. Wang G, Mao W, Zheng S, Ye J. Epidermal growth factor receptorregulated miR-125a-5p - a metastatic inhibitor of lung cancer. FEBSJ. 2009;276(19):5571-5578.

36. Liu X, Sempere LF, Ouyang H, et al. MicroRNA-31 functions as an oncogenic microRNA in mouse and human lung cancer cells by repressing specific tumor suppressors. J Clin Invest. 2010;120(4):1298-1309.

37. Wu X, Xiao H. miRNAs modulate the drug response of tumor cells. Sci China C Life Sci. 2009;52(9):797-801.

38. Ranade AR, Cherba D, Sridhar S, et al. MicroRNA 92a-2*: a biomarker predictive for chemoresistance and prognostic for survival in patients with small cell lung cancer. J Thorac Oncol. 2010;5(8):1273-1278.

39. Xie L, Chen X, Wang L, et al. Cell-free miRNAs may indicate diagnosis and docetaxel sensitivity of tumor cells in malignant effusions. $B M C$ Cancer. 2010;10:591.

40. Zhu W, Zhu D, Lu S, et al. miR-497 modulates multidrug resistance of human cancer cell lines by targeting BCL2. Med Oncol. 2012;29(1): 384-391.

41. Sarkar FH, Li Y, Wang Z, Kong D, Ali S. Implication of microRNAs in drug resistance for designing novel cancer therapy. Drug Resist Updat. 2010;13(3):57-66.

42. Ceppi P, Mudduluru G, Kumarswamy R, et al. Loss of miR-200c expression induces an aggressive, invasive, and chemoresistant phenotype in non-small cell lung cancer. Mol Cancer Res. 2010;8(9): 1207-1216.

43. Liu M, Wang J, Huang H, Hou J, Zhang B, Wang A. miR-181a-Twist1 pathway in the chemoresistance of tongue squamous cell carcinoma. Biochem Biophys Res Commun. 2013;441(2):364-370.

44. Chen Y, Zhang L. MiR-200 family and cancer: function, regulation and signaling. Surg Oncol. Epub March 18, 2014.

45. Grosso S, Doyen J, Parks SK, et al. MiR-210 promotes a hypoxic phenotype and increases radioresistance in human lung cancer cell lines. Cell Death Dis. 2013;4:e544.

46. Castro RE, Ferreira DM, Afonso MB, et al. miR-34a/SIRT1/p53 is suppressed by ursodeoxycholic acid in the rat liver and activated by disease severity in human non-alcoholic fatty liver disease. $J$ Hepatol. 2013;58(1):119-125.

47. Duan W, Xu Y, Dong Y, Cao L, Tong J, Zhou X. Ectopic expression of miR-34a enhances radiosensitivity of non-small cell lung cancer cells, partly by suppressing the LyGDI signaling pathway. $J$ Radiat Res. 2013;54(4):611-619.
48. Luzhna L, Kovalchuk O. Modulation of DNA methylation levels sensitizes doxorubicin-resistant breast adenocarcinoma cells to radiation-induced apoptosis. Biochem Biophys Res Commun. 2010;392(2):113-117.

49. Chaopatchayakul P, Jearanaikoon P, Yuenyao P, Limpaiboon T. Aberrant DNA methylation of apoptotic signaling genes in patients responsive and nonresponsive to therapy for cervical carcinoma. Am J Obstet Gynecol. 2010;202(3):281.e1-281.e9.

50. Qi J, Mu D. MicroRNAs and lung cancers: from pathogenesis to clinical implications. Front Med. 2012;6(2):134-155.

51. Weidhaas JB, Babar I, Nallur SM, et al. MicroRNAs as potential agents to alter resistance to cytotoxic anticancer therapy. Cancer Res. 2007;67(23):11111-11116.

52. Arora H, Qureshi R, Jin S, Park AK, Park WY. miR-9 and let-7g enhance the sensitivity to ionizing radiation by suppression of NFкB1. Exp Mol Med. 2011;43(5):298-304.

53. Jeong $\mathrm{SH}, \mathrm{Wu} \mathrm{HG}$, Park WY. LIN28B confers radio-resistance through the posttranscriptional control of KRAS. Exp Mol Med. 2009;41(12):912-918.

54. Arora H, Qureshi R, Park AK, Park WY. Coordinated regulation of ATF2 by miR-26b in $\gamma$-irradiated lung cancer cells. PLoS One. 2011;6(8):e23802.

55. Babar IA, Czochor J, Steinmetz A, Weidhaas JB, Glazer PM, Slack FJ. Inhibition of hypoxia-induced miR-155 radiosensitizes hypoxic lung cancer cells. Cancer Biol Ther. 2011;12(10):908-914.

56. Lee KM, Choi EJ, Kim IA. microRNA-7 increases radiosensitivity of human cancer cells with activated EGFR-associated signaling. Radiother Oncol. 2011;101(1):171-176.

57. Bader AG, Brown D, Winkler M. The promise of microRNA replacement therapy. Cancer Res. 2010;70(18):7027-7030.

58. He XY, Chen JX, Zhang Z, Li CL, Peng QL, Peng HM. The let-7a microRNA protects from growth of lung carcinoma by suppression of k-Ras and c-Myc in nude mice. J Cancer Res Clin Oncol. 2010;136(7): 1023-1028.

59. Trang P, Medina PP, Wiggins JF, et al. Regression of murine lung tumors by the let-7 microRNA. Oncogene. 2010;29(11):1580-1587.

60. Chen Y, Zhu X, Zhang X, Liu B, Huang L. Nanoparticles modified with tumor-targeting scFv deliver siRNA and miRNA for cancer therapy. Mol Ther. 2010;18(9):1650-1656.

61. Wiggins JF, Ruffino L, Kelnar K, et al. Development of a lung cancer therapeutic based on the tumor suppressor microRNA-34. Cancer Res. 2010;70(14):5923-5930.

62. Boudreau RL, Martins I, Davidson BL. Artificial microRNAs as siRNA shuttles: improved safety as compared to shRNAs in vitro and in vivo. Mol Ther. 2009;17(1):169-175.

63. Elmén J, Lindow M, Schütz S, et al. LNA-mediated microRNA silencing in non-human primates. Nature. 2008;452(7189):896-899.

64. Obad S, dos Santos CO, Petri A, et al. Silencing of microRNA families by seed-targeting tiny LNAs. Nat Genet. 2011;43(4):371-378.

65. Ebert MS, Neilson JR, Sharp PA. MicroRNA sponges: competitive inhibitors of small RNAs in mammalian cells. Nat Methods. 2007;4(9): $721-726$.

66. Roybal JD, Zang Y, Ahn YH, et al. miR-200 Inhibits lung adenocarcinoma cell invasion and metastasis by targeting Flt1/VEGFR1. Mol Cancer Res. 2011;9(1):25-35.

67. Jiang YW, Chen LA. MicroRNAs as tumor inhibitors, oncogenes, biomarkers for drug efficacy and outcome predictors in lung cancer (review). Mol Med Rep. 2012;5(4):890-894. 


\section{Publish your work in this journal}

OncoTargets and Therapy is an international, peer-reviewed, open access journal focusing on the pathological basis of all cancers, potential targets for therapy and treatment protocols employed to improve the management of cancer patients. The journal also focuses on the impact of management programs and new therapeutic agents and protocols on patient perspectives such as quality of life, adherence and satisfaction. The manuscript management system is completely online and includes a very quick and fair peer-review system, which is all easy to use. Visit http://www.dovepress.com/testimonials.php to read real quotes from published authors.

Submit your manuscript here: http://www.dovepress.com/oncotargets-and-therapy-journal 